\title{
Short-term memory in the pigeon using a modified autoshaping paradigm
}

\author{
RICHARD O. STRAUB \\ University of Michigan, Dearborn, Michigan 48128 \\ ROBERT W. WORSHAM \\ John N. Dempsey Regional Center, Putnam, Connecticut 06260 \\ and \\ H. S. TERRACE \\ Columbia University, New York, New York 10027
}

\begin{abstract}
Most investigations of short-term memory in the pigeon have employed the delayed matchingto-sample (DMTS) paradigm. Generally, the limits of retention in these studies have been 15$20 \mathrm{sec}$. In the present experiment, pigeons were tested with a visual short-term memory task that is based upon autoshaping. On some trials, the birds were shown a horizontal line for 5 sec, followed by a variable retention interval, a 5-sec green stimulus, and, finally, a 4-sec food presentation. On other trials, a 5-sec vertical line was followed by a variable retention interval, a 5-sec green stimulus, and no food. Response latencies and rates to the green stimulus were recorded as measures of retention. Horizontal trials generated higher rates and shorter latencies to green than did vertical trials. In contrast to DMTS performance, discrimination was maintained with no significant decrement at retention intervals up to 20 sec. Possible reasons for this discrepancy and the potential usefulness of this paradigm as a memory task are discussed.
\end{abstract}

The earliest systematic laboratory studies of the delayed-response task were carried out by Hunter (1913). The main purpose of his research program was to show that symbolic processes occurred in nonhuman organisms as well as in humans.

Since Hunter (1913) had noticed species differences in the ability to perform well on the delayed-response task, researchers spent the next 30 years investigating phylogenetic differences. The task was considered to be a way of comparing different species in terms of intelligence. In general, these efforts have tended to be disappointing, since the limit for any particular species was constantly being revised upward, depending upon the particular testing procedure and the apparatus used. This problem was somewhat like the problems experienced by psychometricians in designing proper intelligence tests for unbiased crosscultural comparisons.

The current emphasis in research with delayedresponse procedures in animals is on the study of memory processes per se, rather than on species comparison. More specifically, the task most commonly used with monkeys (D'Amato, 1973; Moise, 1970) and with pigeons (Roberts, 1972; Roberts \& Grant, 1976; Zentall,

Portions of this article were presented at the Animal Behavior Society Northeast Regional Meeting, New York, 1976. The research was partially supported by a National Science Foundation Summer Fellowship to the second author. Requests for reprints should be sent to Richard O. Straub, Behavioral Sciences Department, University of Michigan-Dearborn, 4901 Evergreen Road, Dearborn, Michigan 48128.
1973) has been the delayed matching-to-sample, or DMTS, paradigm. In this technique, on each trial, the subject is briefly presented with a simple geometric form or color stimulus that is to be remembered. At the end of some delay interval, the subject is presented with two choice stimuli, one of which matches the previous sample stimulus. A response to the matching stimulus produces a food reward, and a response to the nonmatching stimulus does not. Performance on this task is relatively high at short delay intervals, but it gradually deteriorates as the delay or retention interval is extended, until chance performance is reached with pigeons at delays of about $20 \mathrm{sec}$ (cf. Roberts \& Grant, 1976).

The DMTS paradigm has been considered the "vacuum" in which trace decay, a postulated cause of shortterm forgetting, can be studied. We disagree with this view for several reasons, among which are the facts that performance on DMTS drops off so rapidly as delay intervals are lengthened and that matching as a concept does not easily generalize to novel stimuli (Roberts \& Grant, 1976). In short, DMTS seems to be biologically biased against the pigeon.

Honig and Wasserman (1981) have argued that the relatively poor performance of animals in DMTS experiments may be attributable to procedural rather than memory phenomena. Honig and Wasserman found more rapid acquisition of a simple delayed discrimination (DD) by pigeons than of a delayed conditional discrimination (DCD). The DD procedure is based upon a para- 
digm reported by Konorski (1959) in which discrimination depends upon memory for the sample stimulus alone rather than the conjoint evaluation of sample and test stimuli (DCD and DMTS procedures.)

The purpose of the present study was to devise a simplified short-term memory paradigm derived from a task on which the pigeon excels, autoshaping.

\section{METHOD}

\section{Subjects}

The subjects were four experimentally naive White Carneaux pigeons maintained at $80 \% \pm 3 \%$ of their free-feeding weights throughout the experiment.

\section{Apparatus}

Training and testing were conducted in two identical operant conditioning chambers. The pigeon's portion of each chamber was $30.5 \mathrm{~cm}$ wide, $33 \mathrm{~cm}$ deep, and $30 \mathrm{~cm}$ high. Three walls and the ceiling were white molded plastic. The fourth wall was an aluminum panel painted flat black. It contained one response key $(2.54 \mathrm{~cm}$ in diameter) centered $20 \mathrm{~cm}$ above the floor of the chamber. The key could be illuminated from behind with a horizontal line, a vertical line, or a diffuse green. The food hopper opening was directly beneath the response key, approximately $6 \mathrm{~cm}$ above the floor. Programming of events and recording of data were accomplished by a PDP-8/e computer.

\section{Procedure}

Stage 1. After having been trained to eat reliably from the food hopper, the birds were run for 20 daily sessions, 30 trials/ day, on a nondifferential autoshaping procedure. Each trial started with the presentation of either a horizontal or a vertical line (15 trials/day of each) for $10 \mathrm{sec}$. The line stimulus was followed by $4 \mathrm{sec}$ access to food. Trials were separated by an average of $48 \mathrm{sec}$.

Stage 2. During the second stage, the birds received 27 sessions of differential training. These sessions differed from the first stage only in that vertical line presentations were no longer followed by food. Horizontal presentations terminated, as before, with $4 \mathrm{sec}$ access to food. The purpose of this segment of the experiment was to establish a discrimination between the horizontal and vertical line components.

Stage 3. During the next stage of the experiment, a retrieval cue situation (upon which the subsequent memory task would be based) was established. Each trial presented one of the line components for $5 \mathrm{sec}$, immediately followed by a 5 -sec presentation of a green stimulus. Trials on which the horizontal line had appeared were still followed by food, but in this and subsequent stages, after the green stimulus. Trials on which a vertical line had appeared were never followed by food. These conditions were in effect for 28 sessions. During this stage, the computer recorded pecks and peck latencies only to the green component of each trial.

Stage 4. During this final training phase, a "retention" interval was placed between the termination of the line component and the appearance of the green stimulus. For 29 sessions, the birds experienced a 2 -sec retention interval spent in the totally darkened chamber before the green retrieval cue appeared. The logic behind this procedure was that, if the birds remembered which line stimulus had been presented, they should behave appropriately to the green retrieval cue after the retention interval. That is, they should show high response rates and short response latencies on horizontal trials and low rates and long latencies on vertical trials.

Stage 5. Following training with the fixed retention interval, the birds experienced 20 sessions in which a variable retention interval $(2,6$, or $10 \mathrm{sec})$ was placed between the line component and the green retrieval cue on each trial. All other testing conditions remained the same as in the fourth stage. The combination of trial type (horizontal or vertical) and retention interval resulted in six different trial conditions, each of which occurred five times within each 30-trial session.

Stage 6. This stage was a replication of the testing conditions of the fifth stage with the exception that, during these 21 sessions, the variable retention intervals employed between the line component and the green retrieval cue were 2,10 , and $20 \mathrm{sec}$.

\section{RESULTS}

One bird was dropped from consideration during data analysis because his pecking rate fell to practically zero on both horizontal and vertical trials.

Figure 1 presents mean peck rates and latencies during horizontal and vertical trials for the final five sessions of Training Stages 2, 3, and 4. During Stages 2 and 3 , these data refer to responses to the line stimulus. For Stage 4, these measures refer to responses to the green retrieval cue that followed the line stimulus and the 2 -sec retention interval. Separate bar graphs are presented for each of the three subjects. During horizontal trials, all subjects responded with higher peck rates and shorter response latencies than they did during vertical trials. Analyses comparing peck rates during horizontal and vertical trials confirmed the discrimination apparent in the top portion of Figure 1 [Stage 2: $t(2)=3.47$, $\mathrm{p}=.036$; Stage 3: $\mathrm{t}(2)=5.35, \mathrm{p}=.015$; and Stage 4: $t(2)=2.69, p=.058]$. Analyses comparing peck latencies during horizontal and vertical trials (bottom panel, Figure 1) corroborate these differences [Stage 2: $t(2)=$ $2.49, \mathrm{p}=.06 ;$ Stage 3: $\mathrm{t}(2)=4.16, \mathrm{p}=.03$; and Stage 4: $\mathrm{t}(2)=2.25, \mathrm{p}=.07]$.

Figures 2 and 3 summarize responses and their latencies to the green retrieval cue following the retention intervals employed in Stages $5(2,6$, and $10 \mathrm{sec}$,

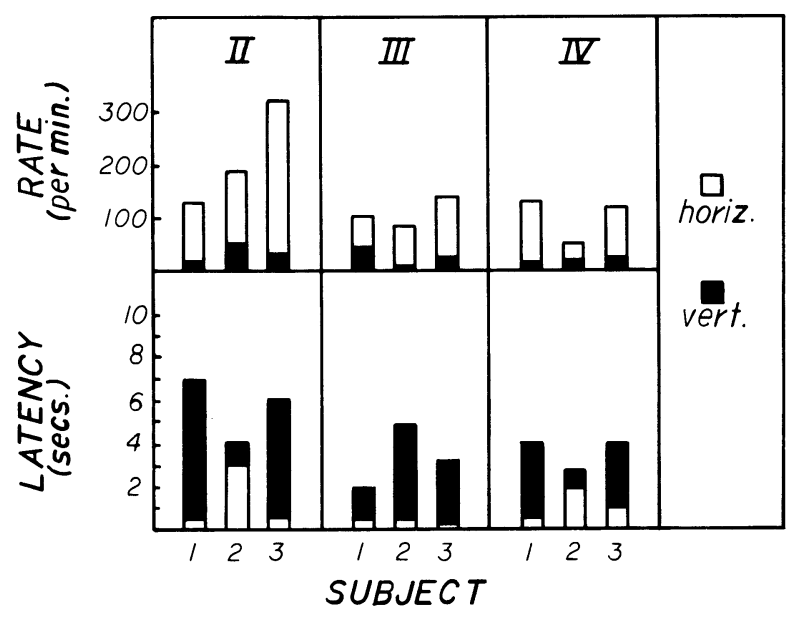

Figure 1. Mean response rates and peck latencies to horizontal and vertical trials. Stage 2: Differential training. Stage 3: Differential training with green retrieval cue (no retention interval). Stage 4: Differential training with green retrieval cue (2-sec retention interval). 
Figure 2) and $6(2,10$, and $20 \mathrm{sec}$, Figure 3$)$. The data are presented in terms of a discrimination ratio of horizontal to vertical trial performance on these measures. The greater the ratio, the better was the discrimination between horizontal and vertical trials. Analyses of variance were conducted on the measures of total pecks and latencies to the green retrieval cue in both stages. These tests show that the horizontal-vertical discrimination established during training was maintained [Stage 5 (horizontal vs. vertical responses): $\mathrm{F}(1,288)=523.64, \mathrm{p}<.01$; Stage 5 (horizontal vs. vertical latency): $F(1,288)=724.69, p<.01$; Stage 6 (horizontal vs. vertical responses): $F(1,288)=554.00, p<$ .01 ; Stage 6 (horizontal vs. vertical latency): $\mathrm{F}(1,288)=$ $431.74, p<.01]$. These tests confirm that, in each case, performance was above that expected on the basis of chance.

Although the horizontal-vertical discrimination is apparent in these analyses, Figures 2 and 3 give the impression of a slightly downward trend in discrimination ratios as the retention interval was lengthened.
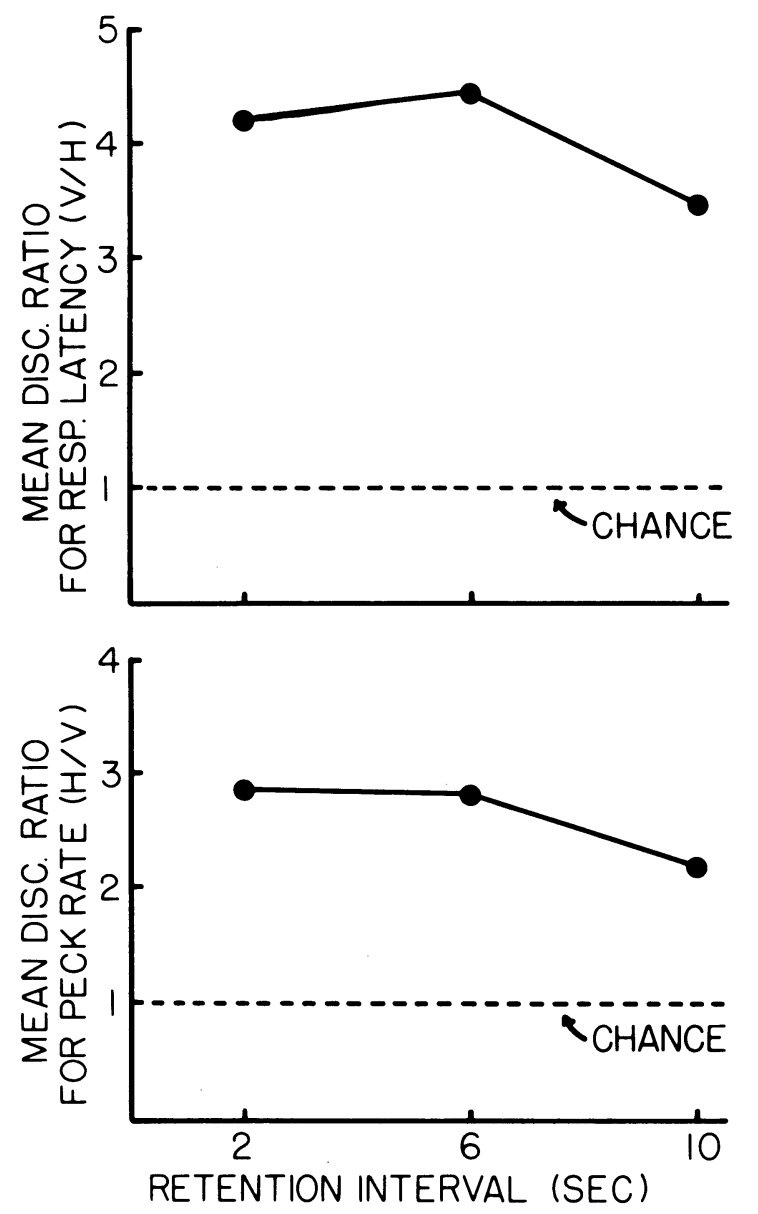

Figure 2. Mean discrimination ratios at retention intervals of 2, 6, and 10 sec. Top panel: Based upon response latencies. Bottom panel: Based upon peck rate.

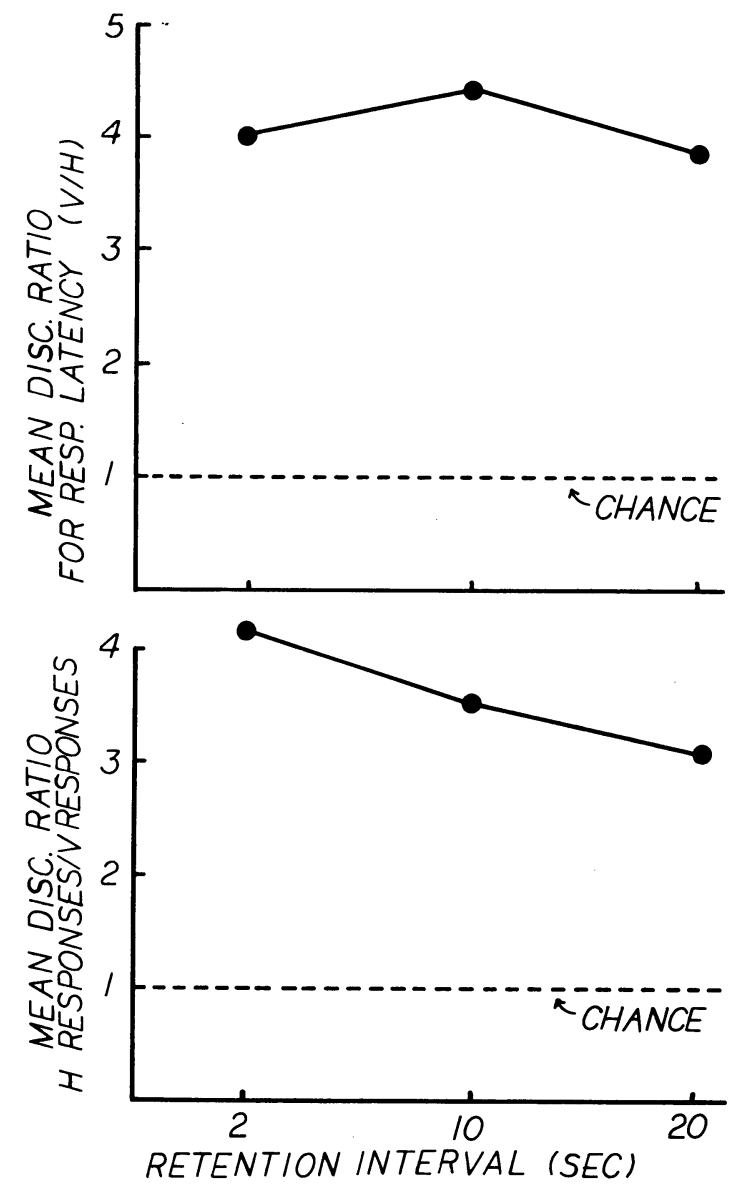

Figure 3. Mean discrimination ratios at retention intervals of 2, 10, and $20 \mathrm{sec}$. Top panel: Based upon response latencies. Bottom panel:Based upon total responses.

Although these are the types of trends that might be seen in a regular memory gradient or forgetting curve, there was no significant interaction between performance differences on horizontal and vertical trials and retention interval. In other words, discrimination was maintained at all retention intervals [Stage 5 (stimulus type by retention interval based upon responses): $\mathrm{F}(2,288)=2.32, \mathrm{p}>.05$; Stage 5 (stimulus type by retention interval based upon response latencies): $\mathrm{F}(2,288)=1.46, \mathrm{p}>.10$; Stage 6 (stimulus type by retention interval based upon responses): $F(2,288)=$ $.0004, p>.10$; and Stage 6 (stimulus type by retention interval based upon response latencies): $F(2,288)=$ $.72, \mathrm{p}>.10]$.

\section{DISCUSSION}

The most important finding of this study is that our subjects showed no significant memory decrements at retention intervals of up to $20 \mathrm{sec}$. This contrasts greatly with most of the memory studies with pigeons that have employed the DMTS paradigm. These techniques typically find that performance is at chance 
levels after delays of only 15-20 sec. At the present time, we do not know how the overall gradient of memory for the autoshaping task looks, but these results do warrant further testing with even longer retention intervals.

There are several possible explanations of the performance discrepancy found between the DMTS and autoshaping procedures. One is that more within-trial interference is generated with DMTS. It is well established that stimuli presented at points in time after the sample terminates can have retroactively interfering effects and cause forgetting. For example, with monkeys (Jarvik, Goldfarb, \& Carley, 1969) and pigeons (Grant \& Roberts, 1976; Zentall, 1973), presentations of visual stimuli similar to the sample during the delay interval disrupt matching. In regular DMTS, without interpolated stimuli, when the choice stimuli are presented after the delay interval, the subject would perceive the incorrect, nonmatching choice stimulus first on approximately half the trials. This is a potential source of retroactive interference that could cause forgetting of the sample stimulus. This type of forgetting is obviously not related to trace decay but may be interpreted as such. The autoshaping procedure, in which retention is measured by performance to a single retrieval cue, is, of course, not subject to such interference.

A second possible difference in the two procedures is that the two types of tasks may be based upon different types of memory traces that have different decay rates. It seems that DMTS performance could only be based upon the visual trace of what the sample stimulus had been. As already noted, several studies have shown that visual stimuli on the response key (Jarvik et al., 1969) and even illumination of the chamber houselight during the retention interval (D'Amato, 1973) disrupt DMTS performance. In contrast, stimuli from another modality (e.g., white noise) are less disruptive of DMTS with visual samples (D'Amato \& Worsham, 1972).

In our autoshaping task, performance could conceivably be based upon a trace of kinesthetic feedback resulting from the way the bird had behaved toward the line component (pecked or not pecked). It could be based upon a classically conditioned excitatory or inhibitory response that lasts through the delay. It could be based upon a visual trace of the line component. Or it could be based upon any combination of these.

We do have preliminary data that suggest that, in mediating the retention intervals in the autoshaping procedure, subjects might rely upon some form of nonvisual representation of the line-component stimuli. These data are based upon several sessions of the present experiment conducted with two subjects following Stage 6. In these sessions, although the retention intervals and format of trials were the same as in the sixth stage, the retention intervals were spent, not in darkness (as in Stage 6), but with the chamber houselight turned on. Although there was an initial disruption of performance, the horizontal-vertical discrimination to the green retrieval stimulus was maintained $[F(1,72)=153.38, p<.01]$, in spite of the houselight as a potential source of visual retroactive interference.

Regardless of which of these factors differentiated the autoshaping and DMTS procedures, we believe that the autoshaping paradigm has certain advantages over the DMTS task. Since the autoshaping task employs only one response key, there is no opportunity for key-position biases to occur, as they often do in multiple-key situations such as DMTS. In the autoshaping task, the dependent variables on any given trial, peck rate and latency, are continuously variable, whereas in DMTS, each trial has only a binary outcome of correct or incorrect choice. In the autoshaping task, the retrieval cue at the end of the delay interval is always the same green stimulus, regardless of what the line component was. This more closely approximates a recall task and does not generate the potential for retroactive interference by the presentation of two choice stimuli. The last advantage of the autoshaping task is that there is absolutely no response contingency whatsoever from the subject's point of view. It always receives the same number of food presentations no matter what it does. This fact may reduce the effects of frustrative emotional reactions that result from errors in response-contingent procedures.

\section{REFERENCES}

D'Amato, M. R. Delayed matching and short-term memory in monkeys. In G. H. Bower (Ed.), The psychology of learning and motivation: Advances in research and theory (Vol. 7). New York: Academic Press, 1973.

D'Amato, M. R., \& Worsham, R. W. Delayed matching in the capuchin monkey with brief sample durations. Learning and Motivation, 1972, 3, 304-312.

Grant, D. S., \& Roberts, W. A. Sources of retroactive inhibition in pigeon short-term memory. Journal of Experimental Psychology: Animal Behavior Processes, 1976, 2, 1-16.

Honig, W. K., \& Wasserman, E. A. Performance of pigeons on delayed simple and conditional discriminations under equivalent training procedures. Learning and Motivation, 1981, 12, 149170.

Hunter, W. S. The delayed reaction in animals and children. Behavior Monographs, 1913, 2, 1-86.

JARvix, M. E., Goldfarb, E. L., \& Carley, J. L. Influence of interference on delayed matching in monkeys. Journal of Experimental Psychology, 1969, 81, 1-6.

KonorsK1, J. A method of physiological investigation of recent memory in animals. Bulletin de l'Academie Polonaise des Sciences, Series des Sciences Biologiques, 1959, 7, 115-117.

Morse, S. L. Short-term retention in macaca speciosa following interpolated activity during delayed matching from sample. Journal of Comparative and Physiological Psychology, 1970, 73, 506-514.

Roberts, W. A. Short-term memory in the pigeon: Effects of repetition and spacing. Journal of Experimental Psychology, 1972, 94, 74-83.

Roberts, W. A., \& Grant, D. S. Studies of short-term memory in the pigeon using the delayed matching-to-sample procedure. In R. T. Davis, D. L. Medin, \& W. A. Roberts (Eds.), Processes of animal memory. Hillsdale, N.J: Erlbaum, 1976.

Zentall, T. R. Memory in the pigeon: Retroactive inhibition in a delayed matching task. Bulletin of the Psychonomic Society, 1973, 1, 126-128.

(Received for publication December 6, 1982.) 